\title{
COMERCIALIZAÇÃO DE FRUTOS E SUBPRODUTOS NA FEIRA LIVRE DA BR- 316 SENTIDO CAXIAS/MA A TIMON/MA, BRASIL
}

Maria Lindalva Alves da Silva ${ }^{1}$, Guilherme Sousa da Silva ${ }^{2}$, Claudeson de Oliveira Velozo $^{3}$, Werton Francisco Nobre Silva ${ }^{4}$ Gonçalo Mendes da Conceição ${ }^{5}$

1. Mestranda do Programa de Pós-Graduação em Biodiversidade, Ambiente e Saúde do Centro de Estudos Superiores de Caxias da Universidade Estadual do Maranhão (lindalva.maria@hotmail.com)

2. Pós-Graduando em Educação e Ensino de Ciências no Instituto Federal do Maranhão Campus Caxias - Maranhão/Brasil

3. Graduando do Curso de Ciências Biológicas - Licenciatura do Centro de Estudos

Superiores de Caxias da Universidade Estadual do Maranhão

4. Graduado em Geografia - Licenciatura do Centro de Estudos Superiores de

Caxias da Universidade Estadual do Maranhão

5. Professor Doutor da Universidade Estadual do Maranhão/UEMA, Programa de

Pós-Graduação em Biodiversidade, Ambiente e Saúde/PPGBAS.

Recebido em: 05/12/2016 - Aprovado em: 15/12/2016 - Publicado em: 31/12/2016

DOI: 10.18677/Agrarian_Academy_2016b18

\begin{abstract}
RESUMO
Este trabalho teve como objetivo conhecer o perfil socioeconômico e as espécies frutíferas e seus subprodutos derivados comercializados na feira livre da BR-316 no sentindo Caxias/MA a Timon/MA. Para coleta de dados foi utilizada abordagem qualitativa, através do uso de formulário semiestruturado com 15 questões fechadas aplicado a 16 feirantes. Os resultados revelaram que dos 16 feirantes entrevistados, $62,5 \%$ são homens e seis $(37,5 \%)$ são mulheres. Destes, $11(68,75 \%)$ são pardos ou pretos e cinco (31,254\%) são brancos. Quanto a origem dos feirantes, 10 $(62,5 \%)$, são maranhenses, quatro (25\%) são piauienses e dois $(12,5 \%)$ dos estados do Pará e do Ceará. Os feirantes comercializam seus produtos em barracas simples, construídas com madeira e cobertura de palha ou telha, piso de chão batido e as prateleiras feitas de taboas de madeira. A maioria dos frutos nativos comercializados pelos feirantes é proveniente da região do Cerrado e da Amazônia Maranhense. A época da comercialização destes frutos inicia-se partir do final do segundo semestre do ano (meses de novembro e dezembro) e início do primeiro semestre (janeiro a março). Nestes meses os feirantes costumam aumentar a renda, pois, estes frutos têm uma ampla aceitação pelas pessoas que trafegam pela rodovia. Os espécimes nativos mais comercializados são: cupuaçu, bacuri e pequi que aumentam a renda familiar dos feirantes na época da safra.
\end{abstract}

PALAVRAS-CHAVE: Bacuri, Buriti, Cupuaçu, Pequi, Renda familiar 


\title{
COMERCIALIZATION OF FRUITS AND BY-PRODUCTS IN THE FREE FAIR OF BR-316 SENSE CAXIAS/MA TO TIMON/MA, BRAZIL
}

\begin{abstract}
This work aimed to know the socioeconomic profile and fruit species and their byproducts sold at the free trade show of BR-316, sense Caxias / MA to Timon / MA. To collect data, a qualitative approach was used, using a semi-structured form with 15 closed questions applied to 16 marketers. The results revealed that of the 16 marketers interviewed, (62.5\%) are men and six (37.5\%) are women. Of these, 11 $(68.75 \%)$ are brown / black and five $(31,254 \%)$ are white. Regarding the origin of the fairs, $10(62.5 \%)$ are from Maranhao, four (25\%) are from Piaui and two from the states of Pará and Ceara. The fair sells its products in simple tents, built with wood and straw or tile cover, beaten floor and shelves made of wooden taboas. Most of the native fruits marketed by the marketers come from the Cerrado region and the Maranhense Amazon. The time of commercialization of these fruits starts from the end of the second half of the year (November and December) and the beginning of the first semester (January to March). In these months, the fair sellers usually increase the income, because, these fruits have a great acceptance of the people that travel by the highway. Native specimens more commercialized are cupuaçu, bacuri and pequi that increase the family income of the marketers at the time of harvest.
\end{abstract}

KEYWORDS: Bacuri, Buriti, Cupuaçu, Pequi, Family income.

\section{INTRODUÇÃO}

O Brasil é um dos principais produtores de frutos do mundo, além de muitos serem nativos, há uma variedade de não nativos, mas que foram introduzidos no país em abundância (CARVALHO \& MIRANDA, 2008 citado por BRAZIL MY COUNTRY, 2016). Neste contexto, o Brasil é conhecido como a "terra das frutas", devido à variedade de frutíferas encontradas, com formatos, perfumes, sabores, tamanho e cores diferentes, característica de um país predominantemente tropical (CARDIM, 2012).

A produção de frutas é uma atividade agrícola que garante a sobrevivência de boa parte de pequenos produtores, fomentando a geração de emprego e renda para as populações que vivem no campo, sendo uma atividade que exige cuidados especiais e atenção por parte do produtor para a obtenção de um produto de qualidade com aceitação no mercado, como por exemplo, um produto de bom tamanho, boa aparência e sabor que atenda ao paladar dos consumidores. A produção de frutos é caracterizada pelo cultivo de pequenos produtores em pequenas áreas e em diferentes regiões brasileiras em todas as épocas do ano (HORTIBRASIL, 2013).

O acesso ao mercado e a comercialização de produtos agrícolas da AF (Agricultura Familiar) constitui um dos principais gargalos para os pequenos produtores, com a escolha do mecanismo de comercialização, envolvendo ações que se adaptem a pequena escala, ao tipo de qualificação do trabalho, ao relacionamento com fornecedores, clientes e prestadores de serviços e a existência de estratégias competitivas (TRENTO et al., 2011). Para estes autores, o processo de comercialização tem início com a produção, mas não se limita a isso, passando pelo beneficiamento, embalagem, compra, venda e atividades de logística. Essa dinâmica de produção, para permanência no mercado, implica que os produtores 
tenham volume, qualidade, diversidade e regularidade de oferta, pois os consumidores precisam se alimentar diariamente e os fornecedores devem estar estruturados.

Nas considerações de ALMEIDA \& PENA (2011), a feira livre é um espaço comunitário que viabiliza o encontro de pessoas de vários locais ou regiões permitindo uma convivência momentânea ou cotidiana dos feirantes e consumidores, que diariamente utilizam para aquisição de produtos para o consumo.

Em decorrência da escassez de estudos sobre a comercialização de frutos e subprodutos em feiras livres nas rodovias brasileiras, o objetivo desta pesquisa foi conhecer as condições socioeconômicas dos feirantes, as espécies frutíferas e os subprodutos derivados comercializados no trecho da BR-316, sentido Caxias/MA a Timon/MA, bem como avaliar as condições estruturais das barracas.

\section{MATERIAL E MÉTODOS}

\section{CARACTERIZAÇÃO DA ÁREA DE ESTUDO}

O povoado Brejinho situa se no município de Caxias/MA, na Mesorregião Leste Maranhense nas seguintes coordenadas geográficas $456^{\prime} 49.85^{\prime \prime} \mathrm{S}$ e $43^{\circ}$ 8'40.60" (IBGE, 2010), com elevação de 132 metros de altitude. O povoado localizase na zona rural a $26 \mathrm{~km}$ da sede do município, às margens da rodovia federal BR316, no KM 582 Sn, no sentindo Caxias/MA a Teresina/PI. O clima predominante da área é o Tropical sub-úmido, com duas estações distintas; verão chuvoso e inverno seco (Figura 1). Neste trecho da rodovia estão instaladas várias barracas, onde os feirantes comercializam frutos e subprodutos derivados em uma feira livre para comunidade local, bem como, aos viajantes que trafegam diariamente pela rodovia.

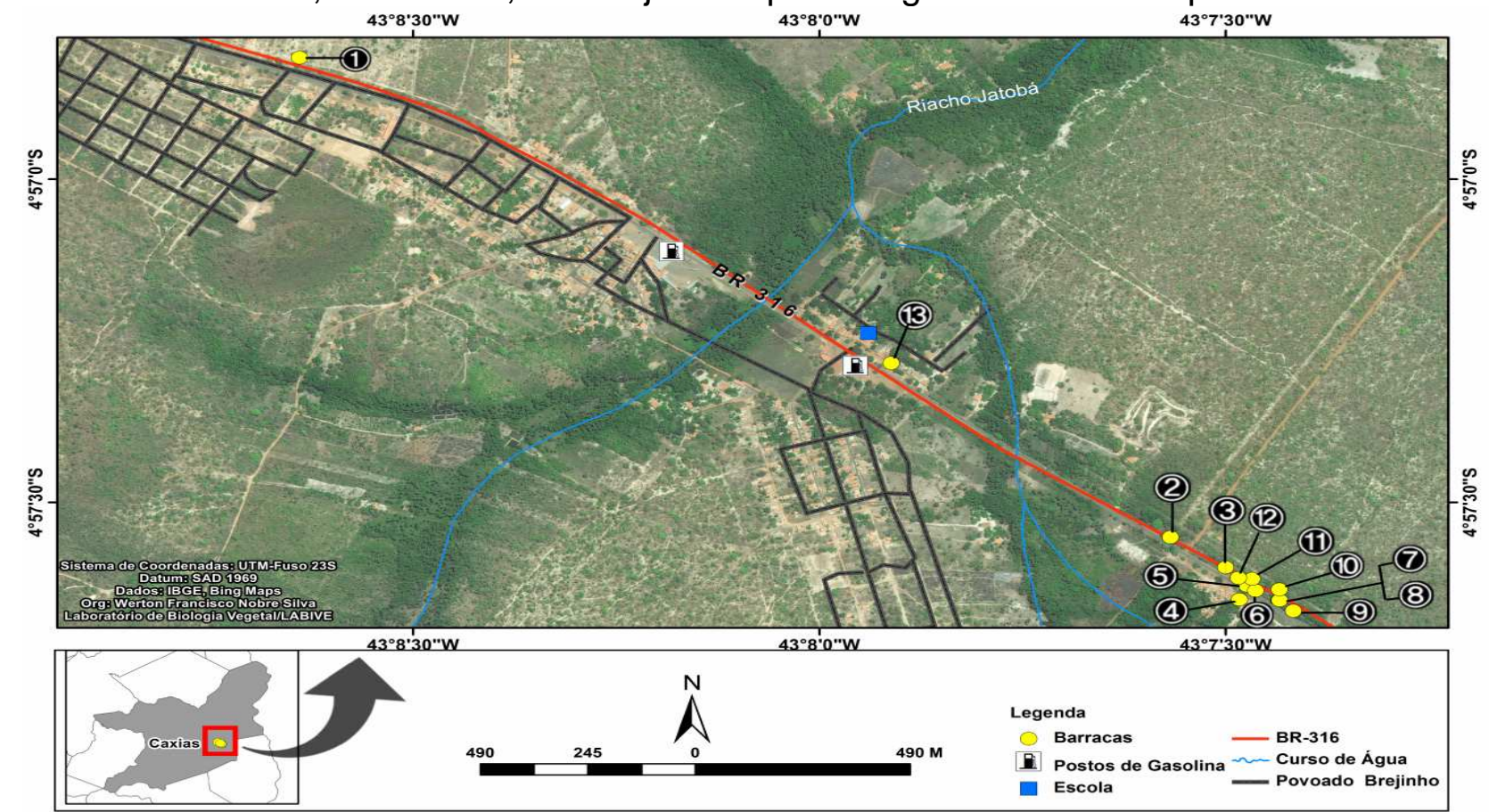

FIGURA 1 - Mapa de localização das barracas instaladas às margens da BR-316, sentido Caxias/MA a Timos/MA. FONTE GOOGLE EARTH, 2016. Organização: SILVA, (2016). 


\section{PROCEDIMENTOS DA COLETA DE DADOS}

Para determinar as técnicas empregadas, durante a pesquisa com vista a colocar o pesquisador em contato direto com o objeto de estudo durante o período de execução das etapas que foram desenvolvidas, optou-se pela pesquisa descritiva, com abordagem de cunho quali-quantitativa. Para realização deste trabalho foi realizado um levantamento bibliográfico como embasamento teórico para as análises dos dados coletados e uma breve discussão de alguns elementos relacionados a conceitos e fundamentos da metodologia de acordo com as considerações de MINAYO (2010). Foram utilizados como instrumentos de coleta de dados; a observação, a entrevista com aplicação de formulários junto aos feirantes com base nos estudos de RICHARDSON (1999) e a localização das coordenadas geográficas das barracas através do uso do GPS (Tabela 1).

Inicialmente foi realizada uma visita prévia para realização de um diagnóstico da área de estudo. Logo após foi elaborado um formulário semiestruturado com 15 questões fechadas com informações sobre as condições socioeconômicas dos feirantes: gênero, raça, idade, estado civil, número de filhos, naturalidade, escolaridade, renda mensal, se a família recebe transferência de renda de programas sociais e tempo que trabalha na ocupação de feirante e informações a respeito da comercialização das espécies de frutos nativos e exóticos e os subprodutos comercializados, época do ano de melhor venda e tipos de frutos mais vendidos. O formulário foi aplicado a 16 feirantes no início do segundo semestre de 2016.

TABELA 1 - Georreferenciamento dos pontos de localização das barracas que comercializam frutos e seus derivados nas margens da BR-316, sentido Caxias/MA a Timon/MA.

\begin{tabular}{|c|c|c|}
\hline Barracas & $S$ & 0 \\
\hline 01 & 456'48.70" & $43^{\circ} 8^{\prime} 38.39^{\prime \prime}$ \\
\hline 02 & 457'33.22" & $43^{\circ} 7^{\prime} 34.10^{\prime \prime}$ \\
\hline 03 & 457'36.03" & $43^{\circ} 7^{\prime} 30.02^{\prime \prime}$ \\
\hline 04 & 457'39.01" & $43^{\circ} 7^{\prime} 29.00^{\prime \prime}$ \\
\hline 05 & 457'37.71" & $43^{\circ} 7^{\prime} 28.46^{\prime \prime}$ \\
\hline 06 & 457'38.19" & $43^{\circ} 7^{\prime} 27.80^{\prime \prime}$ \\
\hline 07 & 457'39.06" & $43^{\circ} 7^{\prime} 26.06^{\prime \prime}$ \\
\hline 08 & 457'39.09" & $43^{\circ} 7^{\prime} 26.04^{\prime \prime}$ \\
\hline 09 & 457'40.07" & $43^{\circ} 7^{\prime} 25.01^{\prime \prime}$ \\
\hline 10 & 457'38.08" & $43^{\circ} 7^{\prime} 26.05^{\prime \prime}$ \\
\hline 11 & $4^{\circ}=57^{\prime} 37.09^{\prime \prime}$ & $7^{\circ} 728.06 "$ \\
\hline 12 & 457'37.01" & $43^{\circ} 7^{\prime} 29.07^{\prime \prime}$ \\
\hline 13 & $457^{\prime} 17.06 "$ & $43^{\circ} 7^{\prime} 54.71^{\prime \prime}$ \\
\hline
\end{tabular}

Após levantamento dos dados, os mesmos foram tabulados no programa Excel 2013 e utilizada estatística simples e representação através de gráficos com análise descritiva para melhor compreensão dos resultados. 


\section{RESULTADOS E DISCUSSÃO}

De acordo com o formulário aplicado, os dados revelaram que dos 16 feirantes entrevistados, $10(62,5 \%)$ são homens e seis $(37,5 \%)$ são mulheres, indicando a predominância dos homens na atividade de feirante nas margens da rodovia BR-316 no povoado Brejinho. Destes, 11 (68,75\%) são pardos ou pretos e cinco $(31,254 \%)$ são brancos. Entre os pesquisados, oito (50\%) são solteiros, seis casados e dois que são indicados pela variável outros, convivem "juntos", ou seja, vivem em união estável. Com relação ao número de filhos, nove $(56,25 \%)$, declararam ter dois filhos, enquanto que dois afirmaram ter cinco filhos $(12,5 \%)$ e cinco entrevistados disseram não ter filho $(31,25 \%)$. Sobre a idade dos entrevistados, cinco $(31,25 \%)$, tem entre 31 a 40 anos, quatro $(25 \%)$ disseram ter entre 21 a 30 anos, três $(18,75 \%)$ com idade até 20 anos, três (18,75\%) de 41 a 50 anos e um com mais de 60 anos.

Quanto ao nível de escolaridade, os dados são demonstrados na Figura 2. 0 maior percentual foi de feirantes que possuem ensino fundamental e médio incompleto. De acordo com conversas informais, alguns feirantes estão concluindo 0 ensino fundamental na modalidade da Educação de Jovens e Adultos (EJA) e o ensino médio no período noturno.

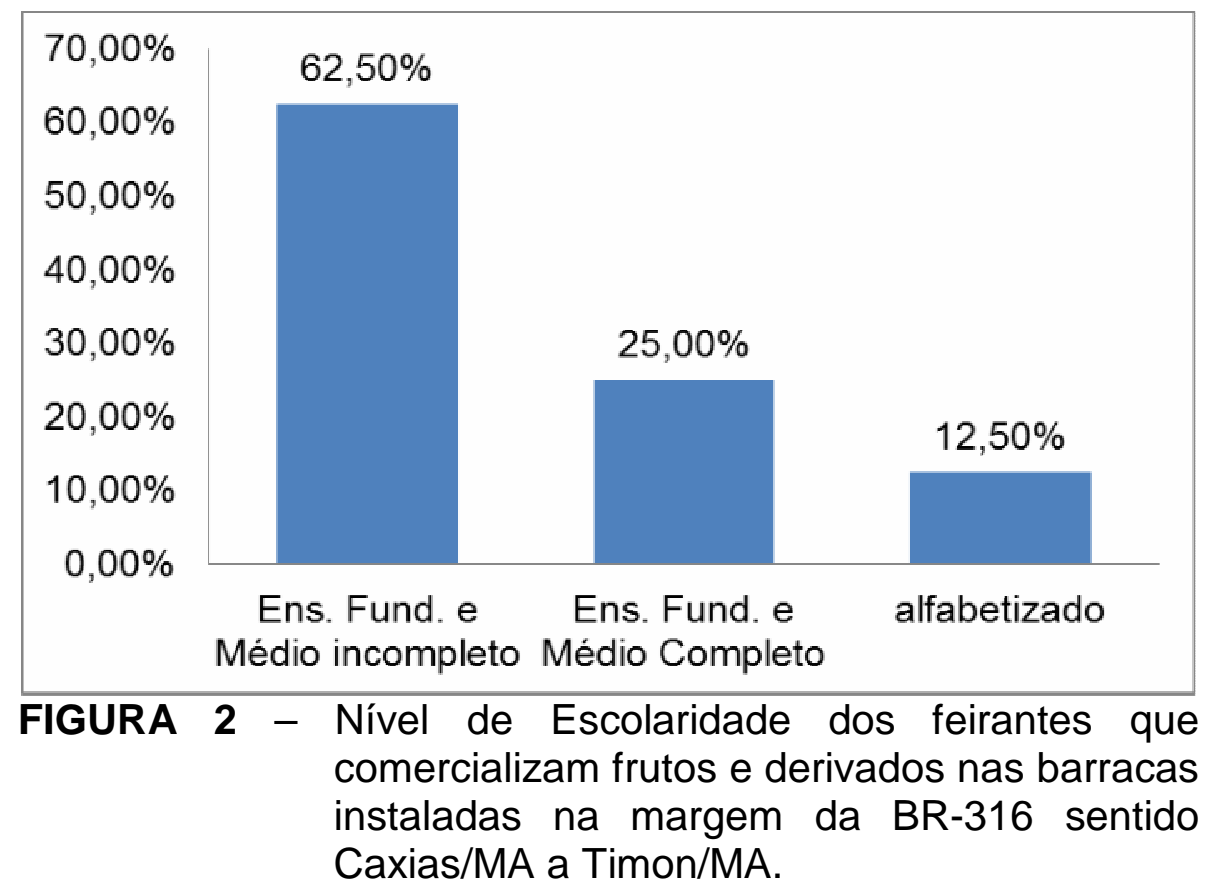

Sobre a origem dos feirantes, $10(62,5 \%)$, são maranhenses, quatro $(25 \%)$ são piauienses e dois (12,5\%) são oriundos dos estados do Pará e do Ceará. Quanto aos dados relacionados ao tempo de permanência como feirante 13 $(81,25 \%)$ estão nesta ocupação a cinco anos como mostra a Figura 3. Neste contexto, os feirantes para RIBEIRO (2007) realizam um movimento considerado pequeno, e como atendem uma parcela restrita, as feiras livres têm pouca atenção do poder público, se comparada ao movimento econômico que promovem, visto que as feiras geram ocupação, renda e identidade regional, muitas vezes, estas se expandem ao invés de reduzirem.

Apesar da existência de mercados e de supermercados nos centros urbanos, de acordo com MAMED-ALI \& MENELAU (2014), as feiras livres são responsáveis 
pela distribuição e comercialização junto a população, no entanto, ainda a estrutura de comércio a varejo e baixos custos, desempenham um papel de relevância nas ofertas dos alimentos, promovendo atendimento as necessidades das populações de menor renda.

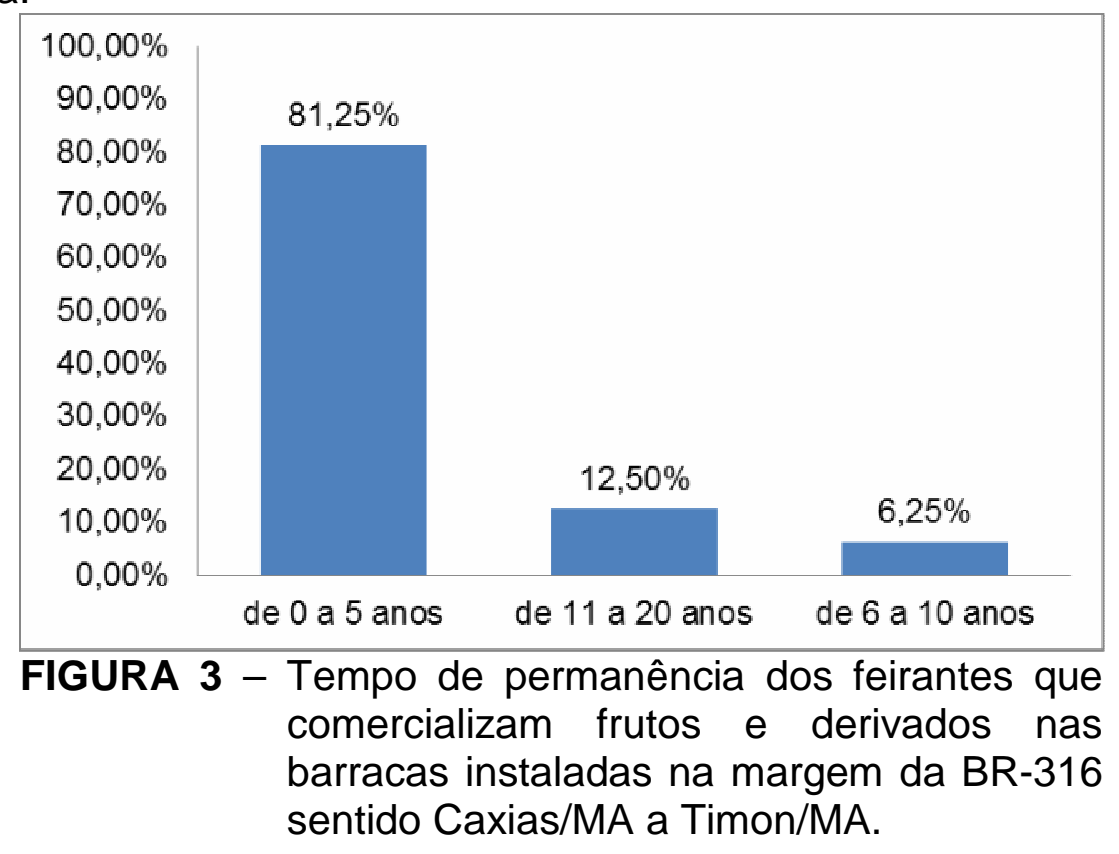

A renda mensal de $56,25 \%$ dos feirantes, de acordo com os dados, é de um salário mínimo (Figura 4). Verificou-se através de observações diretas um fluxo de pessoas da própria comunidade, bem como, de viajantes nas imediações das barracas, comprando os produtos ofertados pelos feirantes, tornando claro que a comercialização dos frutos e subprodutos têm ajudado na economia local e na garantia das condições de sobrevivência dos feirantes.

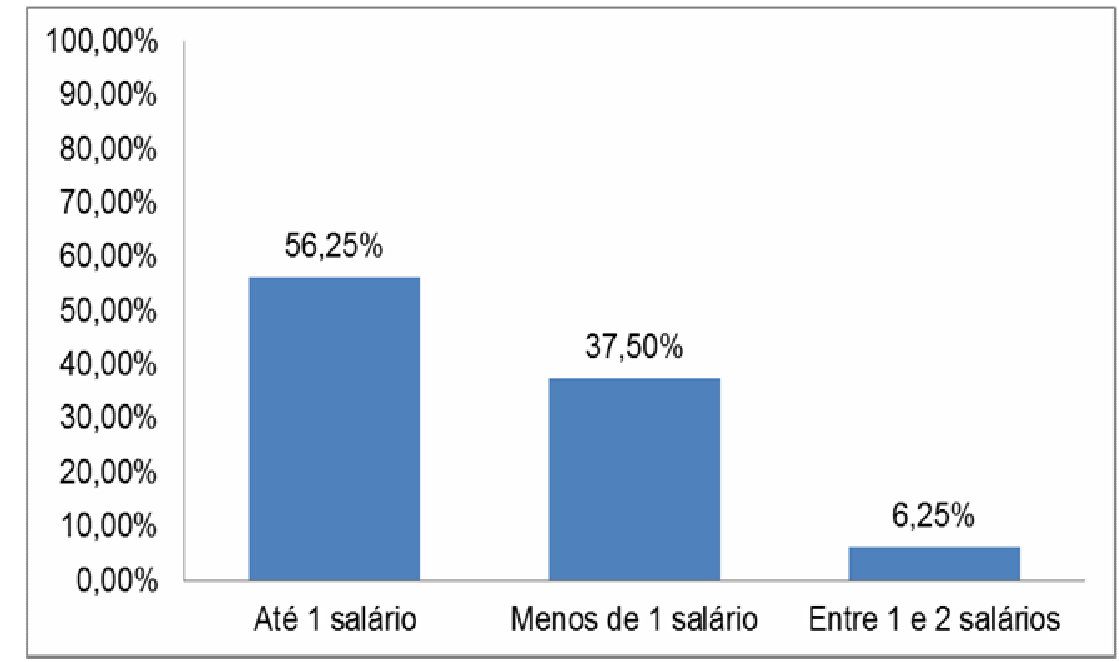

FIGURA 4 - Situação financeira dos feirantes que comercializam frutos e derivados nas barracas instaladas na margem da BR-316 sentido Caxias/MA a Timon/MA. 
Dentre os tipos de espécies botânicas comercializadas nas barracas, verificouse a existência de algumas espécies nativas do Cerrado, conforme a figura 5. A maioria dos frutos nativos comercializados pelos feirantes é proveniente da região do Cerrado e da Amazônia Maranhense. A época da comercialização destes frutos é partir do final do segundo semestre do ano (meses de novembro e dezembro) e início do primeiro semestre (janeiro a março). Nestes meses os feirantes obtêm mais renda, pois estes frutos têm uma excelente aceitação pelas pessoas que trafegam pela rodovia. CANDIDO \& REZENDE (2008), afirmam que os frutos do cerrado apresentam atrativos sensoriais como cor, sabor e aroma peculiares e intensos, açúcares, proteínas, vitaminas e sais minerais e podem ser consumidos in natura ou na forma de sucos, licores, sorvetes, geleias etc.

Com relação a diversidade de espécies botânicas responsáveis pela produção das frutas, o Brasil, se destaca por possuir uma diversidade de campos e florestas propícias a investimentos dos agricultores na produção dessas espécies vegetais. A comercialização desses produtos é de suma importância para manter a renda dos pequenos produtores, bem como, de pessoas como feirantes, vendedores ambulantes e donos de estabelecimentos comerciais que têm como atividade laboral a compra e venda de frutos e derivados (TRENTO et al., 2011).

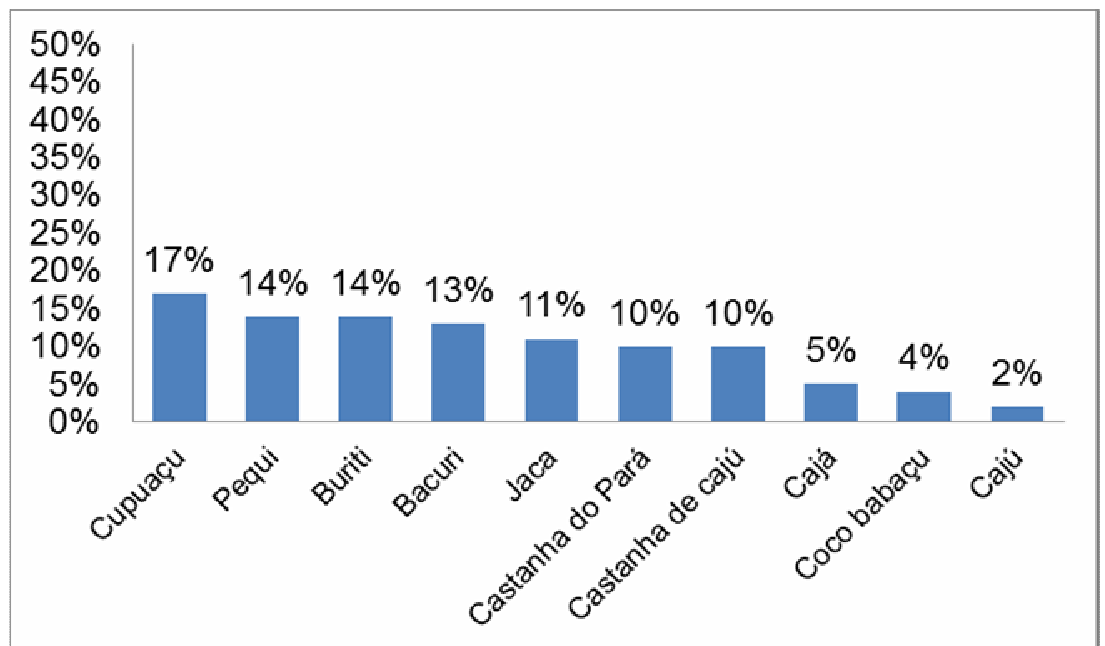

FIGURA 5 - Frutos nativos comercializados pelos feirantes das barracas instaladas na margem da BR316 sentido Caxias/MA a Timon/MA.

Além dos frutos nativos, são comercializados pelos feirantes alguns derivados (Figura 6) como doces, polpas, óleos comestíveis e medicinais. Constatou-se que são comercializados vários subprodutos como doces industrializados e caseiros, polpas, óleos comestíveis produzidos de forma caseira da amêndoa do coco babaçu e óleos medicinais como da copaíba, da mamona, do pequi, da andiroba, alguns destes óleos medicinais são oriundos de outros estados como Pará, Piauí e Ceará. Conforme LEFF (2007), são objetivos do desenvolvimento sustentável: os direitos humanos a um ambiente sadio e produtivo; o valor da diversidade biológica; a conservação da base de recursos naturais e dos equilíbrios ecológicos do planeta; a abertura para uma diversidade de estilos de desenvolvimento sustentável; a satisfação das necessidades básicas e a elevação da qualidade de vida da população; a distribuição da riqueza e do poder por meio da descentralização econômica; o fortalecimento da capacidade de autogestão; a percepção da realidade 
a partir de uma perspectiva global, complexa e interdependente. Sendo assim, a prática de produção de alguns derivados pelos feirantes caracteriza uma forma sustentável de produção.

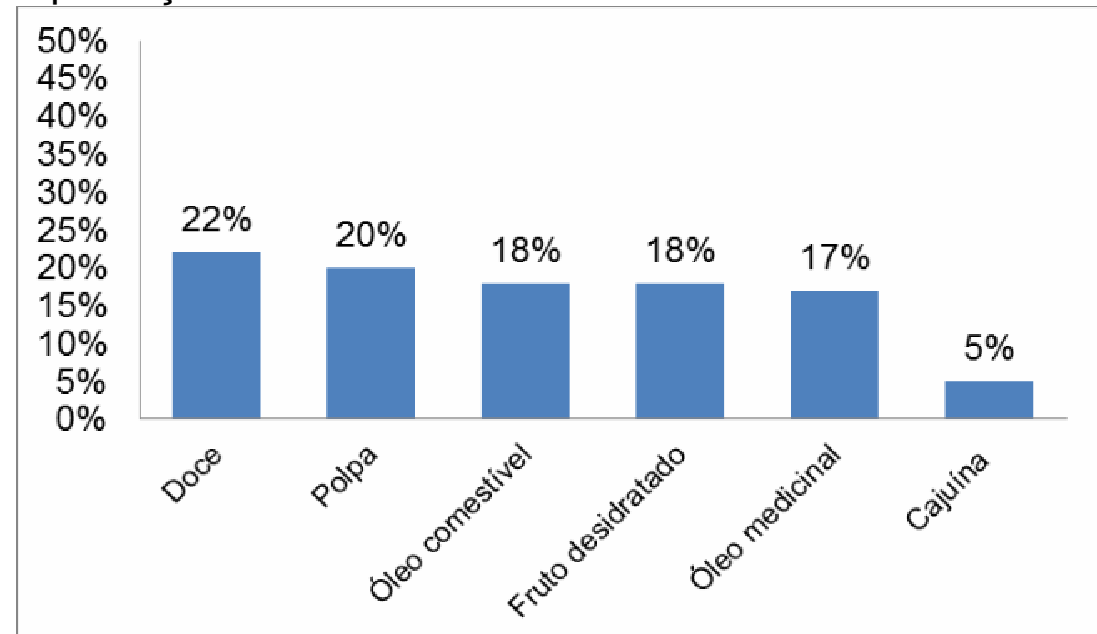

FIGURA 6 - Principais subprodutos comercializados dos frutos nativos pelos feirantes das barracas instaladas na margem da BR-316 sentido Caxias/MA a Timon/MA.

Quando finaliza a época do período de produção dos frutos nativos, os feirantes comercializam outros frutos chamados "exóticos", para suprir a falta dos nativos. Os frutos exóticos mais comercializados são a pimenta $(93,75 \%)$, a manga $(62,5 \%)$ e tangerina (50\%). Além de vender os frutos frescos, também foram constatados alguns derivados conforme Figura 7. Os feirantes são abastecidos semanalmente por caminhões que trazem os frutos e alguns subprodutos para comercialização. No caso da castanha de caju, estas são adquiridas nos estados do Ceará e Piauí.

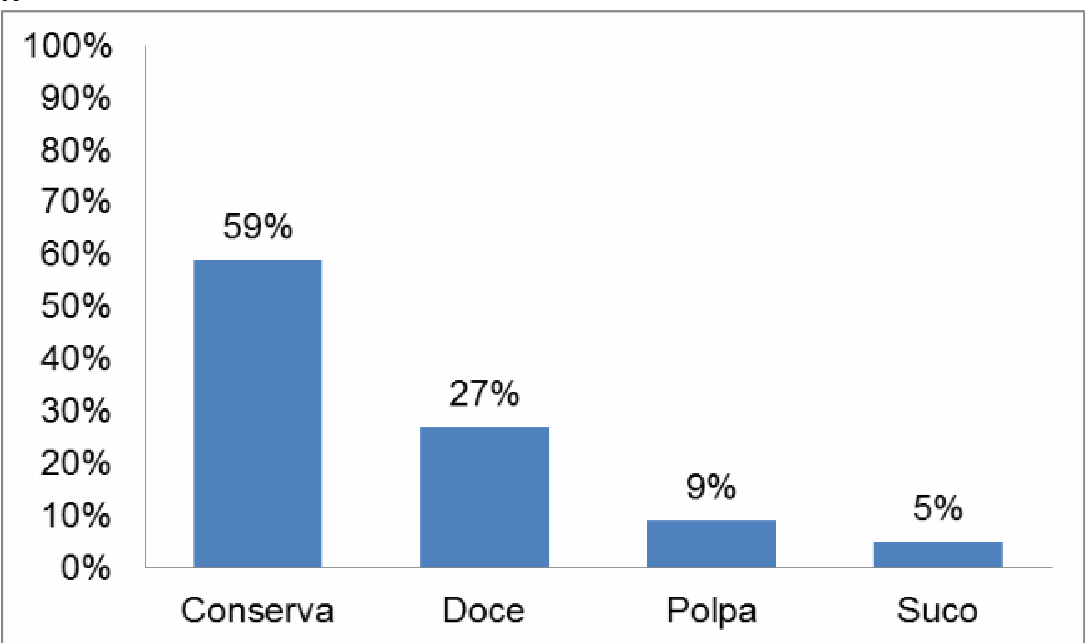

FIGURA 7 - Principais subprodutos comercializados dos frutos exóticos pelos feirantes das barracas instaladas na margem da BR-316 sentido Caxias/MA a Timon/MA.

Indagados sobre a melhor época para comercialização, seis $(37,5 \%)$ concordaram que o período chuvoso é melhor para as vendas e o mesmo número 
de feirante disseram que é o período seco (37,5\%), três (18,75\%) afirmaram que tem uma boa venda durante todo período do ano e um $(6,25 \%)$ não respondeu. $\mathrm{Na}$ opinião da maioria dos feirantes, $13(81,25 \%)$ concordam que são os frutos nativos os mais vendáveis e três $(18,75 \%)$ responderam que são os exóticos. Na concepção de RAMOS (2008), o mercado da fruticultura tropical e exótica está em expansão em âmbito nacional e internacional, favorecendo neste sentido, o desenvolvimento do sistema de cadeias e complexos de produção agroindustrial, integrando regiões e contribuindo para a melhor qualidade da alimentação através do consumo de frutos.

A demanda do consumo de frutos e subprodutos nativos, segundo declarações dos feirantes, cresce em função do poder de compra da população, da preocupação com a saúde e a divulgação nos programas de televisão sobre o valor nutricional que as frutas possuem para o organismo humano. Esta constatação corrobora com as pesquisas de FERREIRA et al. (2005), quando ressaltaram que 0 consumo de frutos cresce principalmente pelo aumento da renda do consumidor e pela composição nutricional, fato associado a busca por melhor qualidade de vida (Figura 8).


FIGURA 8 - Disposição dos frutos nas barracas. Em (A) jaca, (B) castanha de caju, (C) bacuri, (D) Manga, (E) Doces e(F) Conservas. Fonte: SILVA (2016). 
Quanto à estrutura das barracas, as mesmas são construídas apenas com troncos de madeira com cobertura de palha ou telha e piso de chão batido e prateleiras feitas de taboas de madeira necessitando, portanto, de uma infraestrutura mais adequada (Figura 9), pois de acordo com FARIAS et al. (2010), os frutos comercializados em feiras livres requerem cuidados para a comercialização, na maioria desses estabelecimentos de vendas, os produtos são comercializados em bancas de madeira ou expostos em lonas sobre o chão, podendo gerar condições inadequadas para consumo.
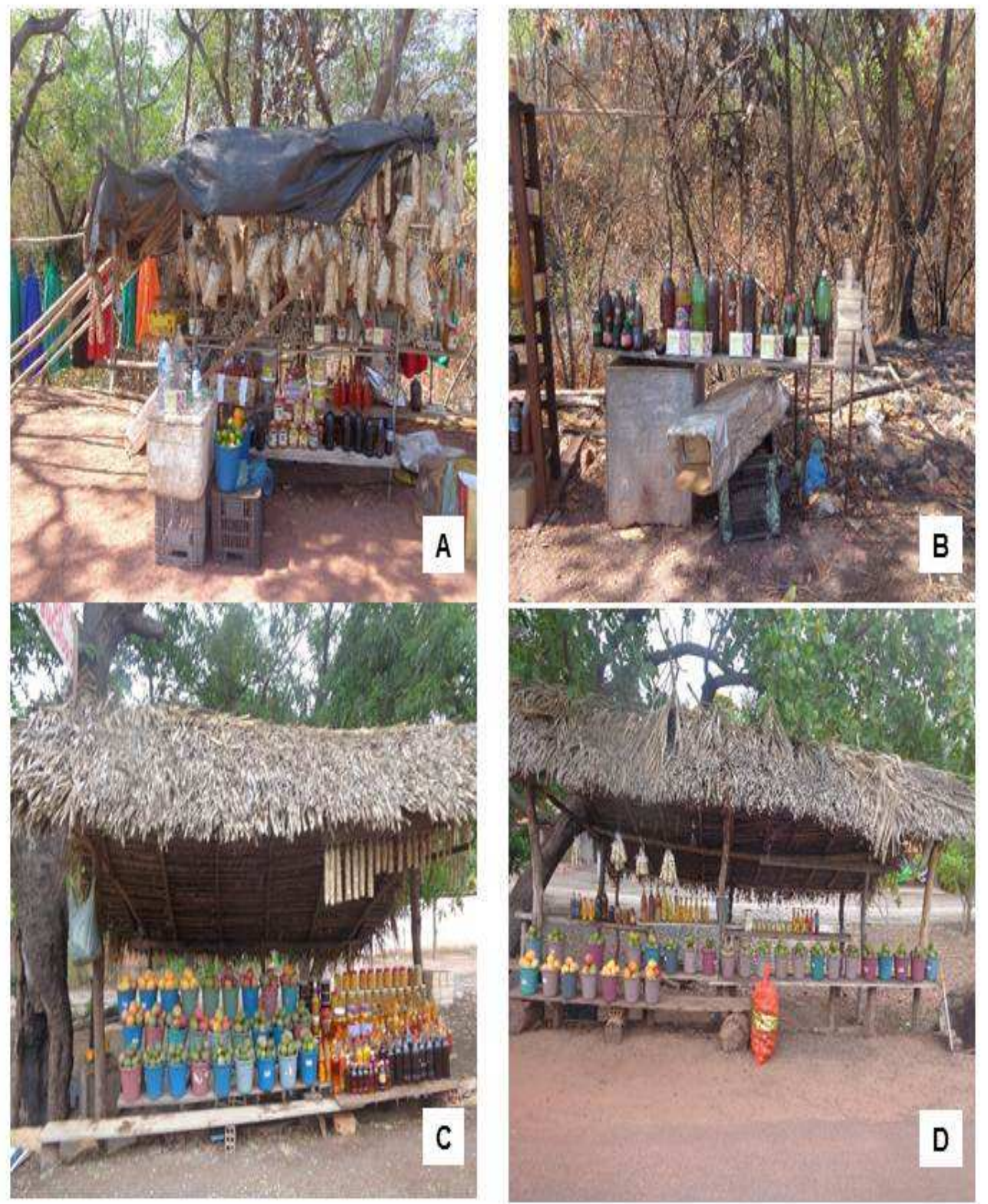

FIGURA 9 - Estrutura das barracas instaladas nas margens da BR/316 sentido Caxias/MA a Timon/MA. Em (A) e (B) barracas improvisadas, (C) e (D) barracas com cobertura de palha de babaçu e estrutura de madeira. Fonte: SILVA, (2016). 
Investigados sobre a forma de acondicionamento dos subprodutos perecíveis como polpas e sucos, os feirantes informaram que estes são colocados em freezers e caixas de isopor com gelo para manter o estado de conservação dos mesmos; doces e conservas industrializados em vidros vedados e os caseiros em recipientes artesanais. Quanto aos frutos frescos como bacuri, pequi, buriti, manga, tangerina e outros, são expostos em baldes de plástico e os desidratados como a castanha de caju e do Pará em sacolas de plástico.

O reconhecimento destas informações é relevante, pois, servem de subsídios ao poder público no que se refere a geração de renda dessas famílias, que dependendo da época da oferta de frutos nativos como pequi, bacuri e buriti, aumenta o fluxo de consumidores, tais como, viajantes de carro passeio, caminhoneiros e transeuntes, o que torna uma maior lucratividade para os feirantes em média/diária de $\mathrm{R} \$ 300,00$. De acordo com RICHARDS \& PATTERSON (2005), as feiras representam importante papel econômico, tanto para produtores, como para consumidores, sendo estas, uma oportunidade de adquirir alimentos com preço baixo e com qualidade.

\section{CONCLUSÕES}

O comércio de frutos e subprodutos às margens da BR-316 é importante porque permite a geração de renda para muitas famílias, além dos feirantes atuarem como distribuidores de frutíferas, colaborando com o desenvolvimento da economia local.

Os feirantes utilizam barracas improvisadas, pois as mesmas são construídas com material rústico, necessitando, portanto, de uma infraestrutura que atenda as condições para acomodar os produtos comercializados e receber o consumidor. Cabe ao poder público dar maior atenção a estes trabalhadores na garantia de melhores condições de vida. Sendo assim, medidas são necessárias no sentido de melhorar a qualidade estrutural das barracas que atendem uma demanda significativa de consumidores que trafegam diariamente neste trecho da BR-316.

\section{REFERÊNCIAS}

ALMEIDA, D. M.; PENA, P. G. L. Feira livre e risco de contaminação alimentar: estudo de abordagem etnográfica em santo amaro, Bahia. Revista Baiana de Saúde Pública. v. 35, n.1, p.110-127, 2011.

BRAZIL MY COUNTRY. BRAZILIAN FRUIT. 2016. Disponível em: http://www.brazilmycountry.com/brazilian-fruits/. Acesso em: 04 de setembro de 2016.

CANDIDO, P. A.; REZENDE, M. L. Estudo da Cadeia Produtiva de Frutos do
Cerrado em $\quad$ Minas $\quad$ Gerais. 2008 Disponível em: http://www.unifalmg.edu.br/geografia/sites/default/files/file/Estudo\%20da\%20cadeia $\% 20$ produt $\% 20$ de $\% 20$ frutos\%20do\%20cerrado\%20em\%20mg.pdf>. Acesso em: 16 de março de 2016.

CARVALHO, J. M.; MIRANDA, D. L. As exportações brasileiras de frutas: Um panorama atual. Apresentação Oral-Comércio Internacional. Universidade de Brasília. Brasília-DF-Brasil. 2008. 
CARDIM, R. Das frutas mais consumidas no Brasil, somente 3 são nativas. ÁRVORES DE SÃO PAULO. 2012. Disponível em: https://arvoresdesaopaulo.wordpress.com/2011/05/15/das-20-frutas-maisconsumidas-no-brasil-somente-3-sao-nativas/. Acesso em: 07 de outubro de 2016.

FARIAS, K. C.; MARTINS, F. F. F.; MARTINS, F.F.; MOREIRA, I.C.M.; JALES, K. A.; ALENCAR, T. C. S. B. D.; SILVA, M. M. G. Avaliação das condições higiênicosanitárias de alimentos comercializados no mercado municipal e na feira livre do município de Hidrolândia-Ce. CONNEPI 2010. Disponível em: <http://connepi.ifal.edu.br/ocs/index.php/connepi/CONNEPI2010/paper/view/1238>. Acesso em 06 de setembro de 2016.

FERREIRA, G. F.; LEMOS, E. E. P.; SOUZA, F. X.; LOURENÇO, I. P.; LEDERMAN, I. E.; BEZERRA, J. E. F.; JÚNIOR, J. F. S.; BARROS, L. M.; RUFINO, M. S. M.; OLIVEIRA, M. E. B.; MENDONÇA, R. M. N.; ALVES, R. E.; ARAÚJO, R. R.; SILVA, S. M.; SOUZA, A. B. Frutíferas. In: SAMPAIO, E. V. S. B. Espécies da flora nordestina de importância econômica potencial. Recife: Associação Plantas do Nordeste, p.49-100, 2005.

HORTIBRASIL. O ICMS e as Frutas e Hortaliças Frescas. 2013. Disponível em: $<$ http://www.hortibrasil.org.br/jnw/index.php?option=com_content\&view=article\&id=1 162:0-icms-e-as-frutas-e-hortalicas-frescas\&catid=50:comercializacão>. Acesso em: 16 de outubro de 2016.

IBGE. Instituto Brasileiro de Geografia e Estatística. Censo 2010. 2010. Disponível em: http://censo2010.ibge.gov.br/ Acesso em: 10 de Dezembro de 2016.

LEFF, E. Epistemologia ambiental.4ํㅡㄹ ed. Revista- São Paulo: Cortez, p. 239, 2007.

MAMED-ALI, V. P.; MENELAU, A. S. Formação de preços nas principais feiras livres associadas aos mercados públicos do Recife. Revista Cientifico. v. 14, n.27, Fortaleza, 2014.

MINAYO, M. C. S. Pesquisa Social: Teoria Método e Criatividade. 29a ed. Petrópolis: Vozes, p. 108, 2010.

RAMOS, E. L. Desenvolvimento sustentável de sistemas de produção de frutas tropicais nativas e exóticas - abordagem mesoanalítica. Revista Sitientibus, Feira de Santana. n. 39, p.53-73, 2008

RIBEIRO, E. M. Feiras do Jequitinhonha: mercados, cultura e trabalho de famílias rurais no semi-árido de Minas Gerais. Banco do Nordeste do Brasil; Universidade Federal de Lavras, Fortaleza, p. 244, 2007.

RICHARDSON, R. J. Observação. In: Pesquisa social: métodos e técnicas. $3^{a}$ ed.ver. Ampl.São Paulo: Atlas. p.259-264,1999.

RICHARDS, T.J; PATTERSON, P.M. A bilateral comparison of fruit andvegetable consumption: United States and Canada. J Agric Res Econ. v. 30, n. 2, p.333-349, 2005. 
SILVA, A. G.; SILVA, V. A. F.; SILVA, M. L.; MACHADO, A. L. Avaliação da condição higiênico-sanitária na comercialização de frutas e hortaliças em feiras livres do município de Luís Gomes/ RN - Brasil. VII CONNEPI. p. 10, 2012.

SILVA, N. J. A.; ALVES, A. F. Agricultura orgânica no município de Maringá-PR: produção e comercialização. In: CONGRESSO DA SOBER, 43, 2013, Ribeirão Preto. Anais. Ribeirão Preto: Sociedade Brasileira de Economia e Sociologia Rural, 2005.

TRENTO, E. J.; SEPULCRI, O.; MORIMOTO, F. Comercialização de Frutas, Legumes e Verduras. Instituto Emater. Curitiba. p. 42, 2011. 